\title{
Modelling Mechanical Response of Geological Fault Structures and their Interaction Analysis with Surrounding Rock
}

\author{
Zhang Yuting ${ }^{1, *}$, Ding Xiuli ${ }^{1}$, Pei Qitao ${ }^{1}$ and Zhang Zhiguo ${ }^{2}$ \\ ${ }^{1}$ Key Laboratory of Geotechnical Mechanics and Engineering of Ministry of Water Resources, Yangtze River Scientific \\ Research Institute, Wuhan, 430010, China \\ ${ }^{2}$ Changjiang Survey, Planning, Design and Research Co.,Ltd, Wuhan, 430010, China
}

\begin{abstract}
The mechanical response of geological fault structure and its interaction with surrounding rock are crucial for the stability of caverns in hard rocks. Geological fault structure exhibits unique mechanical response subjected to rock excavation. Potential failure patterns and their corresponding criterions of geological faults, including open failure, slip failure and block instability, are summarized. Corresponding numerical models and proper supporting measures are recommended for open and slip failures, respectively. Rock damage model is adopted to better illustrate the interaction of rockmass and geological faults. Safety factor for anti-sliding is introduced to quantify the safety extent of caverns subjected to open and slip failures caused by geological faults. Case study shows that the presented methods are effective to describe the mechanical response of geological faults and also to provide quantitative references for reinforcement design of rock caverns.
\end{abstract}

Keywords: Geological fault structure, interaction, mechanical response, numerical analysis.

\section{INTRODUCTION}

The rockmass material, as primary component of Earth's crust, has the complex nature of anisotropy and heterogeneity and is composed by intact rocks and geological discontinuities. Geological discontinuities generally refer to faults, joints and fractures etc. Their appearance in rock engineering projects is unavoidable and makes rockmasses behave quite unique and different from man-made materials, such as cement and metal with known and artificially adjustable mechanical properties.

It is important to use proper numerical approaches to simulate the structural response of geological discontinuities, so as to quantitatively evaluate their influences on rock engineering projects. For rock joints and fractures, numerical models $[1,2]$ have been developed to simulate their mechanical responses and empirical equations have been put forward $[3,4]$ to estimate their shear strength. For geological fault structures, as they have infillings of rock fragments, muddy and debris etc, with certain thicknesses and exhibit different mechanical characteristics, models and equations that are originally intended for rock joints may not be applicable. Numerical methods corresponding to the unique nature of geological fault material are then required. This paper addresses the issue of modelling of mechanical response geological fault structures and its interaction with surrounding rock.

*Address correspondence to this author at the Key Laboratory of Geotechnical Mechanics and Engineering of Ministry of Water Resources, Yangtze River Scientific Research Institute Huangpu Street \#269, Jiangan District, Wuhan, Hubei Province, China; Tel: 0086013971212124 ;

Fax: 0086-027-82926540; Email: magicdonkey@163.com

\section{FAILURE PATTERNS OF GEOLOGICAL FAULT STRUCTURES}

Geological faults are formed after long tectonic period and distribute arbitrarily in rockmasses. There are infillings between the fracture surfaces so their thickness cannot be neglected Fig. (1). When subsurface openings are excavated, traces of geological faults on excavation surfaces may generate different kinds of failures, which become potential threat to rock engineering projects.

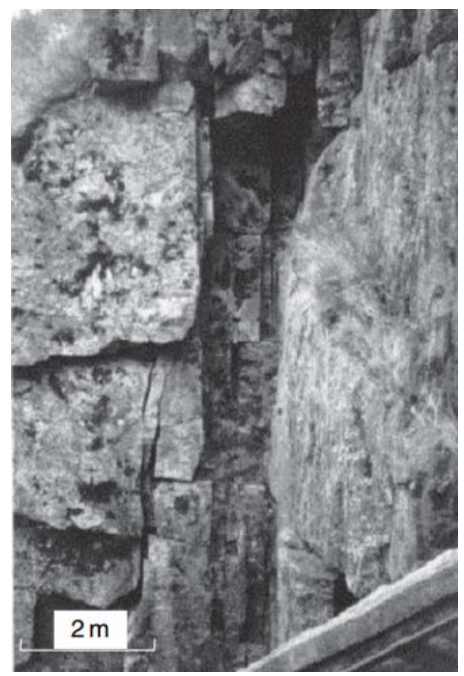

Fig. (1). Fracture zone [5].

Fig. (2). plots the schematic map of typical failure patterns for rock cavern subjected to the impacts of geological faults. 
When fault distributes in anti-inclined occurrence at left sidewall of cavern Fig. (2), surrounding rock at foot wall area will deform inward under excavation effect. As surrounding rock at hanging wall area is restricted, open failure may occur due to different deformation distribution. The open failure of geological faults may lead to many instability issues of surrounding rock, such as cracks, large deformation and toppling failure.

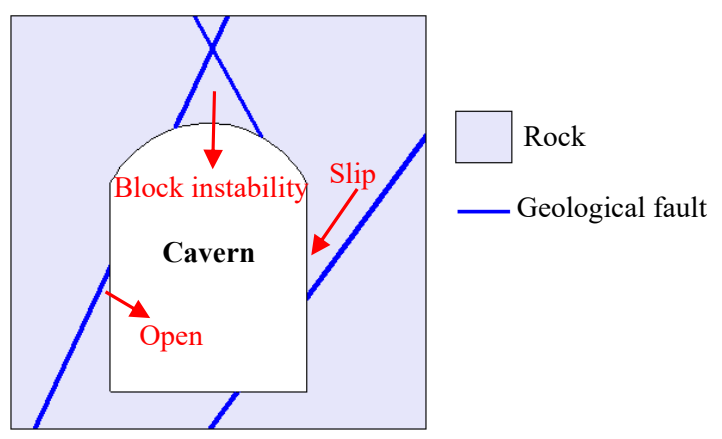

Fig. (2). Schematic map of typical failure patterns caused by geological faults.

When fault distributes in bedding occurrence at right sidewall of cavern Fig. (2), surrounding rock at hanging wall area will probably deform along the fracture surface due to both excavation and gravitation effects. If the infillings of fault structure, in this case, fail to provide sufficient resistant force against sliding deformation, then slip failure may occur. Slip failure of geological faults is also responsible for many safety issues, such as rockmass collapse, large deformation and support failure.

Besides material strength, open and slip failures of geological faults are also depending on their spatial relationship with excavation scheme. Engineers can minimize the negative impacts of geological faults by adjusting the route and orientation design of caverns. Moreover, when geological faults are mutually intersected, block instability is another probable issue that should be addressed. However, block instability issue is not unique for geological faults because it is also usually encountered in rockmasses containing fractures and joints. In this case, block stability not only lies on material strength of geological faults but also depends on the identification and removability of rock blocks. As the latter issue is extensively studied [6-8], focus here is placed on the former one, which emphasizes the mechanical response characteristics of geological fault structures.

\section{NUMERICAL MODELS}

\subsection{Criterions for Determining Failure Patterns of Geological Faults}

From numerical simulation perspective, geological fault should follow certain strain-stress relation laws in the first place to regular its conventional mechanical response subjected to considered loads. The strain-stress relation is given by certain constitutive model. Apart from the adopted constitutive model, additional judgment and treatment are needed to reflect typical failure patterns of geological faults that correspond to their unique material nature. Table 1, for geological faults, summarizes the expression, explanation, criterion, and subsequent treatment of each failure pattern that may occur in numerical analysis. It should be noted that, fracture surface embedding will not occur in actual situations but is necessary for numerical analysis. Block instability is also included because it is a practical failure pattern. The presented criteria, together with constitutve model, constitute the numerical model for geological faults.

\subsection{Rock Damage Model}

Mechanical response of rock material, on the other hand, is also crucial for cavern stability. The interaction between rock and geological fault serves as a primary role of stability analysis of caverns. Although rock material is commonly supposed to deform continuously in continuum mechanics framework, it is still degraded and tiny cracks are generated within rock due to excavation and blasting load. To better illustrate mechanical response of rock material and its interaction with geological fault structures, rock damage model is introduced.

Table 1. Criterions for failure pattern determination of geological faults.

\begin{tabular}{|c|c|c|c|c|}
\hline $\begin{array}{l}\text { Failure } \\
\text { pattern }\end{array}$ & Expression & Explanation & Criterion & Subsequent treatment \\
\hline $\begin{array}{l}\text { Open } \\
\text { failure }\end{array}$ & $F_{t}=\sigma_{n k}-R_{t}$ & $\begin{array}{c}\sigma_{n k}: \text { normal stress of interlayer element. } R_{t}: \text { tensile } \\
\text { strength of geological faults }\end{array}$ & $F_{t}>0$ & $\begin{array}{l}\text { Convert exceeded stress to nodal load and } \\
\text { apply it to adjacent rock elements. }\end{array}$ \\
\hline Slip failure & $\begin{array}{c}F_{s}=\tau_{n k}-\left(f_{k} \sigma_{n k}+\right. \\
\left.C_{k}\right)\end{array}$ & $\begin{array}{l}f_{k} \text { and } c_{k} \text { : friction coefficient and cohesion of } \\
\text { geological faults }\end{array}$ & $F_{s}>0$ & $\begin{array}{l}\text { Convert exceeded stress to nodal load and } \\
\text { apply it to adjacent rock elements. }\end{array}$ \\
\hline $\begin{array}{c}\text { Surface } \\
\text { embed-ding }\end{array}$ & $L=\left|\delta_{1}-\delta_{2}\right|-h$ & $\begin{array}{c}\delta_{1} \text { and } \delta_{2} \text { : displacement increments of } \\
\text { corresponding nodes. } h \text { : original thickness of } \\
\text { geological faults }\end{array}$ & $L>0$ & $\begin{array}{c}\text { Calculate reverse load along normal direction } \\
\text { of fracture plane and apply it to the embedded } \\
\text { nodes. }\end{array}$ \\
\hline $\begin{array}{c}\text { Block } \\
\text { instability }\end{array}$ & $f=\left(F_{c}+F_{f}\right) / F_{s}$ & $\begin{array}{l}F_{c} \text { and } F_{f} \text { : resistant force against sliding provided } \\
\text { by cohesion and friction, respectively. } F_{s} \text { : sliding } \\
\text { force caused by, in many cases, gravity. }\end{array}$ & $f<$ Fos & $\begin{array}{l}\text { Fos is given safety factor. Usually consider } \\
\text { more anchor supporting measures for } \\
\text { reinforcement purpose. } f \text { should be finally } \\
\text { larger than Fos. }\end{array}$ \\
\hline
\end{tabular}


The concept of damage is defined as material degradation caused by mesoscopic structural defects under external loading effects. The behavior of cracks in rock is in accordance with this concept, so degradation of rock can be quantified by using damage concept. With the progressive failure of rock, its strain gradually accumulates. When strain exceeds its limit, rock damage extent, denoted as $D$ and named as damage coefficient, initiates and develops in positive correlation as:

$D=f(\varepsilon)(\varepsilon>[\varepsilon])$

where $[\varepsilon]$ is ultimate strain. When $\varepsilon<[\varepsilon]$, rock damage does not occur and $D=0$. $D$ in one dimensional cases can be described using uniaxial strain as:

$D=1-\left(\varepsilon_{0} / \varepsilon\right)^{2} \quad(\varepsilon>[\varepsilon])$

where $[\varepsilon]$ usually corresponds to ultimate tensile strength. For three dimensional cases, the ultimate tensile strength is difficult to obtain due to technical restrictions. Note that the ultimate tensile strength is in positive correlation with compressive strength and in negative correlation with stiffness, $[\varepsilon]$ can then be calculated by [9]:

$[\varepsilon]=f_{c} / K E$

where $K$ is the safety coefficient, $f_{c}$ is the compressive strength, and $E$ is the elastic modulus of rock. As $\varepsilon$ is a second order tensor, the first principal strain $\varepsilon_{1}$ is used to indicate the beginning of rock damage.

When rock damage initiates, its degradation effect on rock properties is a gradually accelerated process. Exponential function is used to describe this process as:

$D=1-\mathrm{e}^{-R e \mathrm{D}}$

where $e_{D}=\sqrt{e_{i j}^{p} \cdot e_{i j}^{p}}$ and $R$ is damage constant.

\subsection{Stability Evaluation of Caverns Affected by Geological Faults}

Numerical simulation results provide quantitative description of mechanical response of geological fault and rock material subjected to rock excavation effect. The calculation results should be further used to conduct stability evaluation of caverns, so as to provide instructive advices to practical projects. Evaluation methods corresponding to slip and open failure of geological faults are then discussed, respectively.

\section{(1). Open Failure}

It can be seen from Table $\mathbf{1}$ that once stress perpendicular to fracture surface exceeds the tensile strength, it will cause open failure. By converting the exceeded stress to nodal load and applying it to adjacent rock elements, the range of open failure area will develop to inner region of surrounding rock. In this case, the extent of open failure area is important for support design. To prevent triggering progressive failure of surrounding rock, grouting is recommended as favorable treatment measure. The infillings of geological fault can be in this way strengthened and re-bonded, thus increasing the overall stiffness and strength. Generally, the grouting extent should be deep enough to exceed the range of open failure area and the grouting pressure should be appropriate to ensure infilling compactness, so as to achieve expected reinforcement effect.

\section{(2). Slip Failure}

From Table 1, it is found that the expression for slip failure can be re-written as below:

$K=\left(f_{k} \sigma_{n k}+c_{k}\right) / \tau_{n k}$

where $K$ defines the ratio of resistant force to sliding force and can be called safety factor against sliding. Therefore, the safety margin for preventing slip failure can be quantified. Generally, it is required that $K$ should be at least larger than 1.0 so as to prevent slip failure. However, in view of some uncertainties on material parameters and other construction disturbances, $K$ is usually required to meet higher standard, commonly known as $[K]$, for safety purpose. [K] should be larger than 1.0 and is a comprehensive parameter determined based on overall consideration of various factors, such as project significance, service duration, and load combination. To prevent progressive failure triggered by slip failure of geological fault, it is suggested that anchor bolts be adopted to reinforce the identified slip failure area. Because anchor bolts are able to enhance the anti-shear ability of fracture surfaces by bonding rockmasses at foot wall and hanging wall together.

\section{NUMERICAL IMPLEMENTATION}

\subsection{Constitutive Model}

The models given above are then incorporated into calculation platform to realize numerical simulation function. The calculation platform adopted by this paper is developed independently. Zienkiewicz-Pande criterion is adopted as the constitutive model:

$F=\sqrt{-\alpha}\left(\sigma_{m}+\frac{\beta}{2 \alpha}\right)+\sqrt{\left(\bar{\sigma}^{2}+\gamma-\frac{\beta^{2}}{4 \alpha}\right)}$

where $\alpha=-\sin ^{2} \varphi, \beta=2 c \sin \varphi \cos \varphi, \gamma=a^{2} \sin ^{2} \varphi-c^{2} \cos ^{2} \varphi . \sigma_{\mathrm{m}}$ $=\left(\sigma_{1}+\sigma_{2}+\sigma_{3}\right) / 3$. Among these parameters, $c$ is the cohesion, $\varphi$ is the internal friction angle, and $a$ is a coefficient that describes the approaching extent of yield surface.

During excavation process, rock degradation is caused by crack initiation and growth. Within areas where cracks distribute, stress is decreased and stress damage zone forms. The extent of decreased stress can be expressed by damage coefficient $D$ as:

$\sigma_{i j}^{D}=(1-D) \sigma_{i j}+\frac{D}{3} \sigma_{k k} \delta_{i j}$

where $\sigma_{i j}^{D}$ is stress tensor considering damage and $\delta_{i j}$ is Kronecker function.

The differential form of stress tensor $\sigma_{i j}$ with regard to strain tensor $\varepsilon_{i j}$ can be written as:

$\mathrm{d} \sigma_{i j}=\left(\left[D_{e}\right]-\left[D_{p}\right]\right) \mathrm{d} \varepsilon_{i j}$

where $\left[D_{e}\right]$ and $\left[D_{p}\right]$ are elastic and plastic stress matrixes, respectively. Perform differential calculation on (7) according to (8), we have: 
$\mathrm{d} \sigma_{i j}^{D}=(1-D)\left[D_{e p}\right] \mathrm{d} \varepsilon_{i j}+\frac{D}{3}\left[D_{e p}\right] \mathrm{d} \varepsilon_{i j}-S_{i j} \mathrm{~d} D$

If incremental load with each calculation step is sufficiently small, then the damage coefficient $D$ can be viewed as constant during current step and $\mathrm{d} D=0$. So (9) can be simplified and further written as:

$\mathrm{d} \sigma_{i j}^{D}=(1-D)\left[D_{e p}\right] \mathrm{d} \varepsilon_{i j}+\frac{1}{3} D\left[D_{e p}\right] \mathrm{d} \varepsilon_{i j}=\left(\left[H_{e}\right]-\left[H_{d}\right]\right) \mathrm{d} \varepsilon_{i j}$

where $\left[H_{e}\right]=\left[D_{e}\right]$ and $\left[H_{d}\right]$ is stress matrix considering damage as:

$\left[H_{d}\right]=\left(1-D+\frac{D}{3} \delta_{i j}\right)\left[D_{p}\right]+\left(D-\frac{D}{3} \delta_{i j}\right)\left[D_{e}\right]$

\subsection{Iteration Algorithm}

The incremental variable plastic stiffness matrix iteration method is adopted to solve the equation. Within each loading step, the non-linear equations as:

$\left[\bar{K}\left(\left\{\delta_{i}\right\}\right)\right]\left\{\delta_{i}\right\}=\left\{\bar{P}_{i}\right\}$

where $\left\{\bar{P}_{i}\right\}$ is equivalent load and $\left[\bar{K}\left(\left\{\delta_{i}\right\}\right)\right]$ is equivalent stiffness matrix at loading step $i$.

\section{CASE STUDY}

\subsection{Project Outline}

The studied rock engineering project is an underground cavern complex of a hydropower plant at southwestern region of China. Three major geological faults, denoted as F9, F14 and F18, pass through the cavern region. Mechanical parameters are given in Table 2. According to geological survey, fault F9 is about $0.30 \mathrm{~m} \sim 0.45 \mathrm{~m}$ thick, fault F14 is about $0.15 \mathrm{~m} \sim 6.0 \mathrm{~m}$ thick and fault F18 is $4.5 \mathrm{~m}$ thick. The powerhouse cavern is about $291 \mathrm{~m}$ long, $27.3 \mathrm{~m}$ wide and $66.7 \mathrm{~m}$ high.

\subsection{Initial Conditions}

Calculation mesh is firstly established. Totally 71706 elements and 40744 nodes are discretized in the region. It can be seen from Fig. (3). that the faults are intersecting the primary caverns of cavern complex.

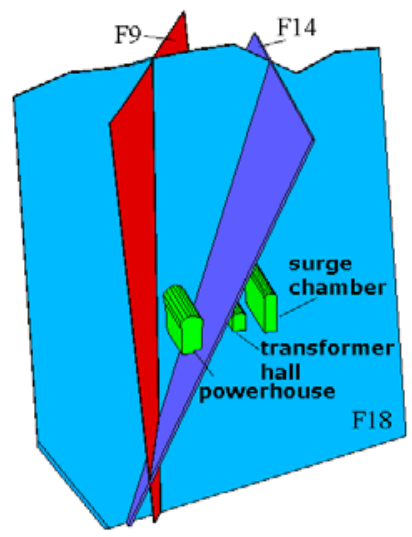

(a) Faults intersecting caverns

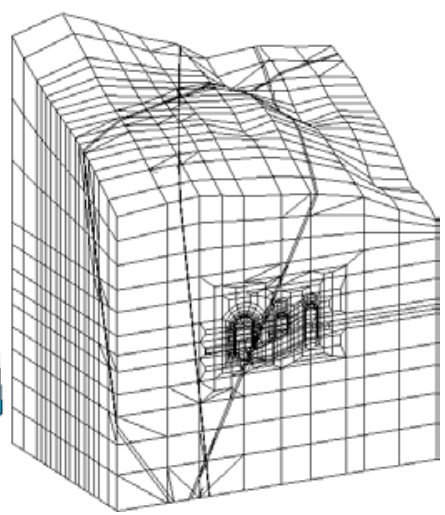

(b) Calculation mesh
Fig. (3). Calculation model for cavern complex.

It can be seen that F9 obliquely intersects the powerhouse cavern. F14 orientation is basically parallel to longitudinal axial direction of major caverns and F18 cross over the major caverns. From the spatial relationship between cavern complex and considered geological faults, it can be roughly estimated that the impacts of geological faults are considerable.

The natural stress in rockmass is determined based on stress regression results. Rock excavation calculation is conducted based on the presented methods.

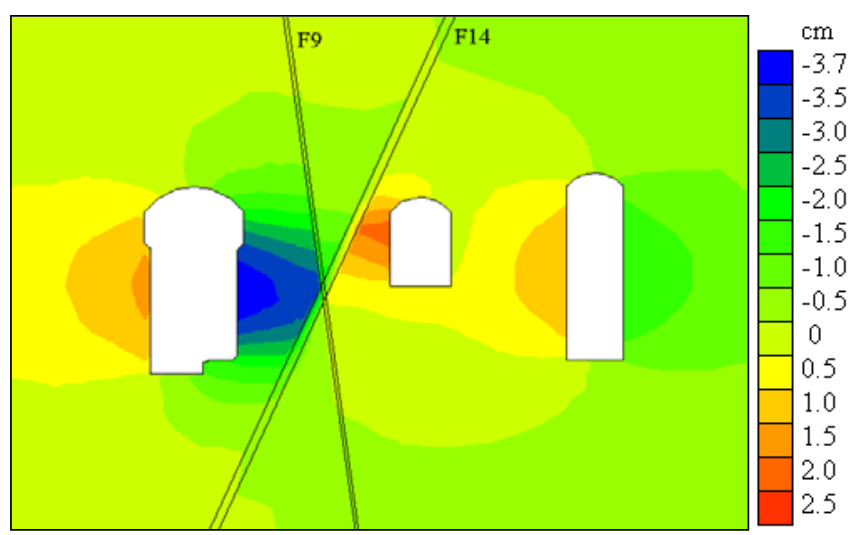

Fig. (4). Surrounding rock deformation.

Table 2. Mechanical properties of materials.

\begin{tabular}{|c|c|c|}
\hline Material & Rock & Geological fault \\
\hline Properties & 2.61 & 2.70 \\
\hline \hline Density (g/cm ${ }^{3)}$ & 15 & 0.50 \\
\hline Elastic modulus (GPa) & 0.26 & 0.35 \\
\hline Poisson's ratio & 1.35 & 0.42 \\
\hline Internal friction angle $\left(^{\circ}\right)$ & 1.5 & 0.1 \\
\hline Cohesion (MPa) & 1.5 & 0 \\
\hline Tensile strength (MPa) & \\
\hline
\end{tabular}




\subsection{Calculation Results}

\section{(1). Surrounding Rock Deformation}

It is found that Fig. (4)., due to geological faults influences, rock pillar between powerhouse and transformer hall shows remarkable discontinuous deformation characteristics. The comparative deformation at hanging wall and foot wall area amounts to $2 \sim 4 \mathrm{~cm}$. Deformation of other surrounding rock area is uniformly distributed and deformation magnitude is also smaller.

\section{(2). Failure Patterns of Geological Faults}

Fig. (5). plots the failure patterns of fault F9 when excavation is completed. It is found that, both open and slip failure occur for this fault. The open failure area only distributes within the shallow and surface area of surrounding rock. The slip failure area is larger and extends to $6 \mathrm{~m}$ depth inward. There is no failure for fault F14. For F18, only slip failure is observed Fig. (6). The numerical findings indicate that both grouting and anchor bolts supporting measures should be adopted to reinforce rockmass.

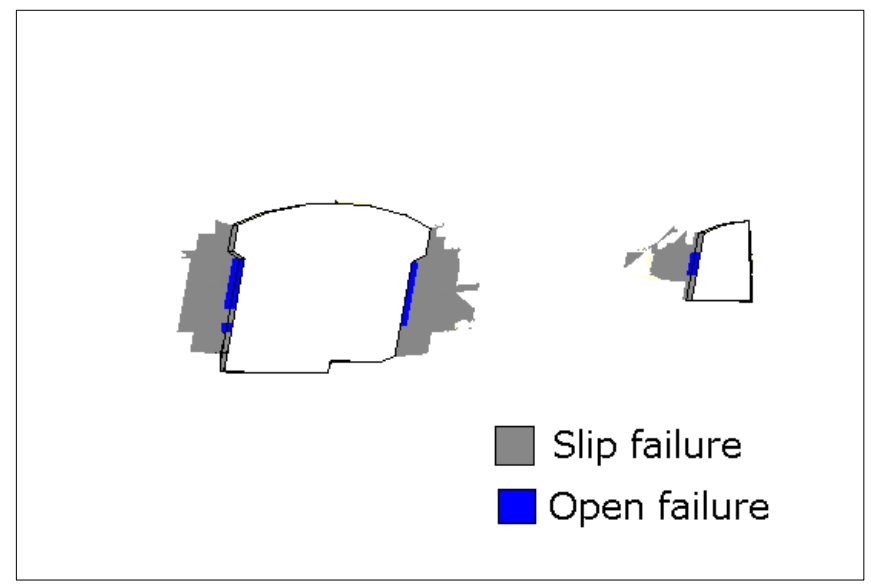

Fig. (5). Failure patterns for fault F9.

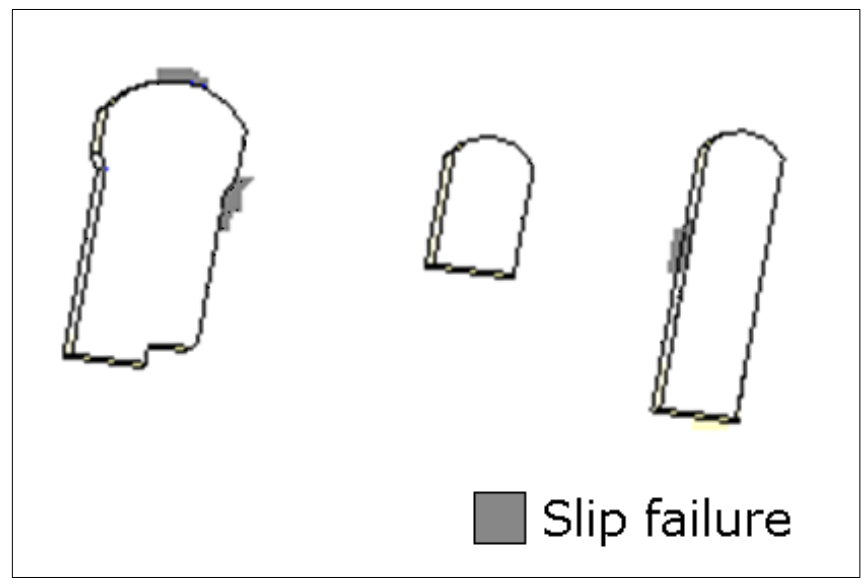

Fig. (6). Failure patterns for fault F18.

\section{(3). Safety factor for anti-sliding}

Fig. (7). and Fig. (8). plot the distribution of safety factor for anti-sliding of F9 and F18, respectively. According to
Table 1, for slip and open failure, the excessive stresses are both converted to nodal forces and applied to adjacent elements. So the minimum value of anti-sliding safety factor is 1 . It can be seen that the region with low safety factor magnitude generally coincides with slip failure area. The safety factor can further quantitatively describe the safety extent of surrounding rock. By considering different safety margins, $[K]$ can be determined and plots its range according to safety factor distribution. The length of supporting measures, especially anchor bolt length index, can be decided.

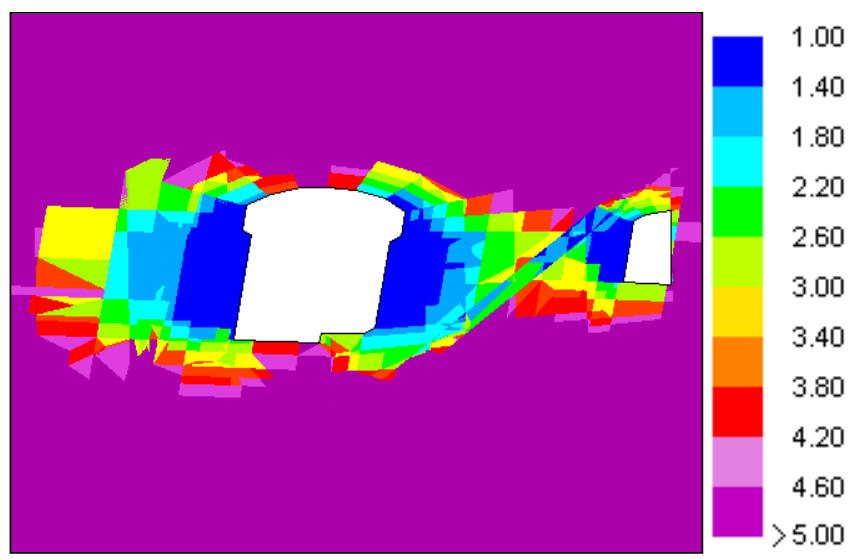

Fig. (7). Safety factor for anti-sliding of fault F9.

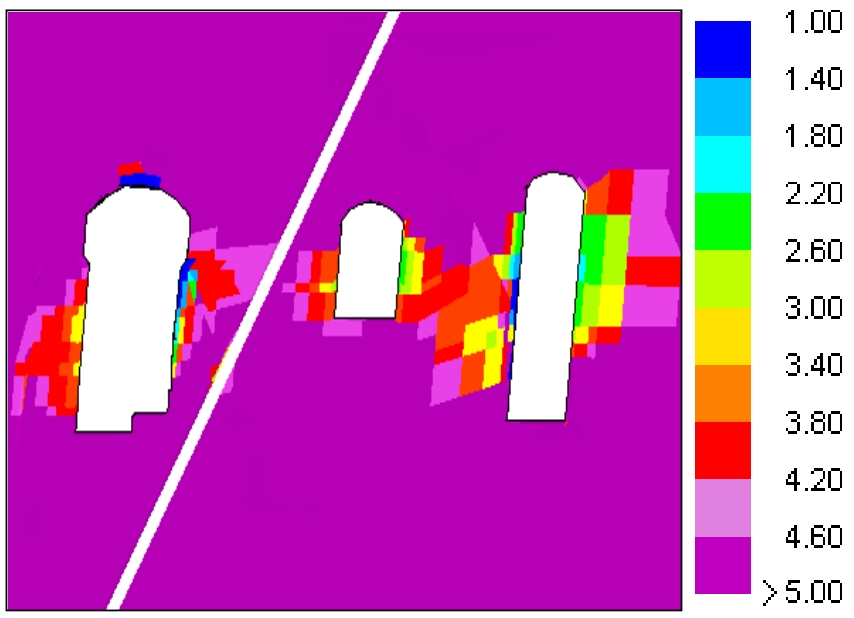

Fig. (8). Safety factor for anti-sliding of fault F18.

\section{CONCLUSION}

Geological faults affect rock cavern stability in terms of several typical failure patterns. These failure patterns are summarized and corresponding numerical models are presented. Rock damage model is also used to better describe the interaction of rock and fault. Case study shows that the proposed method effectively reflects mechanical response of geological faults and their impacts on rockmass. For different failure patterns, corresponding measures are suggested. Numerical simulation results also provide quantitatively references to reinforcement design.

It should be noted that, the proposed method regarding failure pattern classification and corresponding numerical simulation model, are primarily intended for hard rocks 
intersected by geological fault structures with physically weakened properties. Due to the diversity of natural rocks and their occurrence environment, geological discontinuities, such as fractures and fault structures, are only one of the primary factors that cause instability to surrounding rock. For soft and bad rocks, such as limestone and mud stone, etc., their own poor physical properties play a decisive role in determining cavern stability. Therefore, cavern stability under this condition, is to a great extent depending on mechanical response of specific rock entities. This topic should be also attached with sufficient attention and will be addressed in further studies.

\section{CONFLICT OF INTEREST}

The authors confirm that this article content has no conflict of interest.

\section{ACKNOWLEDGEMENTS}

Financial supports from National Natural Science Foundation of China (No. 51209021 and No. 51379022), National Basic Research Program of China (973 Program, No. 2011CB710600), and China Postdoctoral Science Foundation Funded Project(No. 2014M552021) are greatly acknowledged.

\section{REFERENCES}

[1] M. Cai, and H. Horii, "A constitutive model of highly jointed rock masses”, Mechanics of Materials, vol. 6, pp. 217-246, July 1992.

[2] R. E. Goodman, R. L. Taylor, and T. L. Brekke, "A model for the mechanics of jointed rock", Journal of Soil Mechanics \& Foundations Division, vol. 94, pp. 637-659, May 1968.

[3] N. Barton, "The shear strength of rock and rock joints", International Journal of Rock Mechanics and Mining Sciences \& Geomechanics Abstracts, vol. 13, pp. 255-279, August, 1987.

[4] S. Bandis, A. C. Lumsden, and N. R. Barton, "Experimental studies of scale effects on the shear behaviour of rock joints", International Journal of Rock Mechanics and Mining Sciences \& Geomechanics Abstracts, vol. 18, pp. 1-21, February 1981.

[5] L. Jing, and O. Stephansson, Eds., Fundamentals of Discrete Element Methods for Rock Engineering: Theory and Applications, Elsevier Science Ltd, UK: 1987.

[6] C. Gonzalez-Palacio, A. Menedez-Diaz, A. E. Alvarez-Vigil, and C. González-Nicieza, "Identification of non-pyramidal key blocks in jointed rock masses for tunnel excavation", Computers and Geotechnics, vol. 32, pp.179-200, June 2005.

[7] Y. T. Zhang, M. Xiao, and J. T. Chen, "A new methodology for block identification and its application in a large scale underground cavern complex", Tunnelling Underground Space Technology, vol. 25, pp.168-180, March 2010.

[8] Y. T. Zhang, M. Xiao, X. L. Ding, and A. Wu, "Improvement of methodology for block identification using mesh gridding technique", Tunnelling and Underground Space Technology, vol. 30, pp. 217-229, July 2012.

[9] M. Xiao, "Study on Numerical Analysis Method on Stability and Supporting for Underground Caverns", Ph D. thesis, Wuhan University, Wuhan, Hubei, China, 2002.

Received: September 17, 2014 